\title{
Cuscuta L. (Convolvulaceae) na Região Sul do Brasil
}

\author{
(D) $\underline{\text { Priscila Porto Alegre Ferreira }}^{1,5}$, (Dreta Aline Dettke ${ }^{2}$, (D) Rosangela Simão-Bianchini ${ }^{3}$ e \\ (iDSilvia Teresinha Sfoggia Miotto ${ }^{4}$
}

Como citar: Ferreira, P.P.A., Dettke, G.A., Simão-Bianchini, R., \& Miotto, S.T.S. 2021. título completo. Hoehnea 48: e982020. https://doi.org/10.1590/2236-8906-98/2020

RESUMO - (Cuscuta L. (Convolvulaceae) na Região Sul do Brasil). Cuscuta é amplamente distribuído e possui aproximadamente 200 espécies de parasitas volúveis. Estima-se que ocorram 26 espécies no Brasil, porém, não há estudos atuais publicados para a flora do país. Por meio de extensa revisão bibliográfica, de materiais de herbários e expedições a campo, foram reconhecidos 15 táxons de Cuscuta na Região Sul do Brasil (Estados do Paraná, Santa Catarina e Rio Grande do Sul): Cuscuta boliviana, C. campestris, C. corniculata, C. epilinum, C. incurvata, C. indecora var. neuropetala, C. obtusiflora, C. odorata, C. orbiculata, C. platyloba, C. racemosa, C. taimensis, C. xanthochortos var. xanthochortos, $C$. xanthochortos var. carinata e C. xanthochortos var. lanceolata. Uma nova espécie foi descrita (C. taimensis P.P.A. Ferreira \& Dettke) e novas ocorrências para os Estados e uma para o Brasil foram confirmadas durante este estudo. São fornecidas chave de identificação, descrições morfológicas, ilustrações, além de dados de distribuição geográfica e habitat dos táxons. Palavras-chave: cipó-chumbo, escamas infraestaminais, morfologia, plantas parasitas, taxonomia

ABSTRACT - (Cuscuta L. (Convolvulaceae) in Southern Brazil). Cuscuta is widely distributed and comprises about 200 species of parasitic vines. It is estimated that 26 species of Cuscuta occur in Brazil, however, there are no recent published studies concerning the flora of this country. We found fifteen taxa of Cuscuta regarding of the Southern Brazil (Paraná, Santa Catarina e Rio Grande do Sul states): Cuscuta boliviana, C. campestris, C. corniculata, C. epilinum, C. incurvata, C. indecora var. neuropetala, C. obtusiflora, C. odorata, C. orbiculata, C. platyloba, C. racemosa, C. taimensis, C. xanthochortos var. xanthochortos, $C$. xanthochortos var. carinata and $C$. xanthochortos var. lanceolata. One new species was described ( $C$. taimensis P.P.A. Ferreira \& Dettke) and new records were confirmed for states and Brazil. We provide a key to species of Cuscuta, morphological descriptions, illustrations, information about geographic distribution and habitat.

Keywords: dodders, infrastaminal scales, morphology, parasitic plants, taxonomy

\section{Introdução}

Cuscuta L. compreende cerca de 200 espécies parasitas com distribuição sub-cosmopolita, mas com mais de 75\% das espécies nativas da América, ocorrendo em uma grande variedade de ambientes (Costea et al. 2015). Constitui um dos gêneros de plantas parasitas com maior importância econômica, pois algumas espécies causam impactos negativos em culturas agrícolas (Nickrent 2020).

As espécies de Cuscuta exibem reduções extremas de estruturas vegetativas, como resultado de sua adaptação à forma de vida parasita (plantas aclorofiladas, áfilas, ramos geralmente amarelos ou alaranjados com haustórios), limitando os caracteres reprodutivos como diagnósticos para estudos morfológicos (Stefanović et al. 2007). Devido a essa adaptação, a taxonomia de Cuscuta é historicamente controversa, e o gênero já foi segregado em Cuscutaceae em alguns sistemas de classificação (Cronquist 1981, 1988, Takhtajan 1959, 1997, Austin 1998). Porém, estudos moleculares e morfológicos confirmam o seu posicionamento em Convolvulaceae (Stefanović et al. 2002, 2003).
Os principais estudos com Cuscuta são os de Engelmann (1859), a Flora Brasiliensis de Progel (1871) e o de Yuncker (1932). Este último, em uma ampla revisão do gênero, o autor confirmou 165 espécies, e baseado em características do gineceu, reconheceu três subgêneros (subg. Grammica, subg. Eugrammica e subg. Monogyna), apresentando descrições detalhadas para cada táxon e principalmente ilustrações com detalhes das flores, caráter importante para identificar espécies de Cuscuta. Após esta revisão, poucos trabalhos taxonômicos foram realizados (Hunziker 1949, 1950, Feinbrun 1970, Múlgura 1979).

Nas últimas décadas, diversas análises morfológicas e evolutivas com espécies do gênero Cuscuta foram realizadas, descrevendo, por exemplo, a morfologia dos grãos de pólen (Welsh et al. 2010) e das escamas infraestaminais (Riviere et al. 2013) e as estratégias reprodutivas (Wright et al. 2011, 2012). Com base em todas as evidências corroboradas e considerando as recentes análises filogenéticas com o gênero (García \& Martín 2007, Stefanović et al. 2007, García et al. 2014), Costea et al. (2015) classificaram todas as 194 espécies atualmente reconhecidas de Cuscuta em quatro subgêneros: subg.

1. Secretaria do Meio Ambiente e Infraestrutura do Rio Grande do Sul, Jardim Botânico de Porto Alegre, Seção de Coleções, Avenida Dr. Salvador França 1427, 90690-000 Porto Alegre, RS, Brasil

2. Universidade Estadual de Maringá, Avenida Colombo 5790, 87020-900 Maringá, PR, Brasil

3. Instituto de Botânica, Avenida Miguel Estéfano 3687, 041902-000 São Paulo, SP, Brasil

4. Universidade Federal do Rio Grande do Sul, Departamento de Botânica, Avenida Bento Gonçalves 9500, 91501-970 Porto Alegre, RS, Brasil

5. Autor para correspondência: priscila.poaferreira@gmail.com 
Monogynella (15 espécies), subg. Pachystigma (cinco spp.), subg. Cuscuta (três seções e 21 spp.) e subg. Grammica (15 seções e 153 spp., incluindo todas as espécies sul-americanas).

As espécies de Cuscuta são geralmente destacadas pelos seus impactos negativos principalmente em culturas agrícolas (Lanini \& Kogan 2005, Cruz Neto et al. 2017). No entanto, a maioria das espécies não afeta as atividades humanas (Nickrent 2020) e estudos revelaram as propriedades medicinais de alguns táxons do gênero, sendo utilizados em ações anti-inflamatórias, antimicrobianas, hepatoprotetoras e antioxidantes (Donnapee et al. 2014, Ahmad et al. 2017). Além disso, grande parte das espécies atua como espéciechave em seus ecossistemas naturais, e muitas requerem medidas de conservação, pois são endêmicas ou ameaçadas e algumas já são consideradas extintas (Press \& Phoenix 2005, Costea \& Stefanovic 2009). No Brasil, nenhuma espécie é citada em listas vermelhas, tanto na nacional quanto nas regionais, pois faltam dados para avaliação dos táxons.

Para o Brasil, estima-se que ocorram 26 espécies de Cuscuta (Flora do Brasil 2020 em construção). Porém, após a revisão de Progel (1871), não foram publicados trabalhos com o gênero, apenas floras locais (Simão-Bianchini \& Pirani 1997, Simão-Bianchini et al. 2016, Alencar et al. 2019, Bandeira et al. 2019) e uma nova espécie foi descrita por Ferreira et al. (2014). Dois importantes trabalhos foram realizados para as regiões Nordeste (Nepomuceno 2019) e Sudeste (Silva 2020), mas com dados ainda não publicados.

De acordo com as referências disponíveis (Yuncker 1922, 1923, 1932, Austin \& Costea 2008, Simão-Bianchini \& Ferreira 2010), para a Região Sul do Brasil são citados doze táxons de Cuscuta, sendo seis ocorrentes no Estados do Paraná, seis em Santa Catarina e cinco no Rio Grande do Sul.

Este estudo teve como objetivo realizar o levantamento do gênero Cuscuta na Região Sul do Brasil. São fornecidas chave de identificação, descrições morfológicas e ilustrações, além de dados sobre distribuição geográfica, habitat e período de floração e frutificação dos táxons.

\section{Material e métodos}

O trabalho baseou-se em revisão bibliográfica e de herbários, coletas e observações em campo, além do estudo morfológico.

Foram revisadas as coleções de Convolvulaceae e de plantas parasitas dos seguintes herbários (acrônimos de acordo com Thiers 2020), através de empréstimos ou visitas: CRI, FLOR, FUEL, FURB, HAS, HBR, HCF, HUCS, HURG, ICN, MBM, MVFA, NY, PACA, PEL, S, SP e UPCB, além de bases de dados online: CRIA (2020), JBRJ (2020), Reflora (2020).

A Região Sul do Brasil compreende três Estados: Paraná (PR), Santa Catarina (SC) e Rio Grande do Sul (RS), perfazendo uma área total de $576.774 \mathrm{~km}^{2}$. São reconhecidos três Domínios Fitogeográficos: o Pampa (no RS), a Mata Atlântica (nos três Estados) e o Cerrado (no PR). A vegetação consiste em Floresta Ombrófila Densa, Floresta Ombrófila Mista, Floresta Estacional Decidual e Semidecidual, Estepe (Campos do Sul do Brasil), Savana (Cerrado) e Savana Estépica (Parque Estadual do Espinilho) (IBGE 2020).
Foram realizadas excursões aos três Estados da Região Sul para coleta e observação dos táxons, entre os anos de 2009 e 2020. O material coletado encontra-se depositado no Herbário do Instituto de Biociências da Universidade Federal do Rio Grande do Sul (ICN) e no Herbário Alarich Rudolf Schultz (HAS) do Museu de Ciências Naturais, ambos em Porto Alegre, RS, e duplicatas foram destinadas a outros herbários.

A terminologia utilizada segue a literatura especializada no gênero Cuscuta: Yuncker (1932) e Costea et al. (2012, 2015). As medidas das estruturas representam valores extremos encontrados entre os indivíduos analisados.

As ilustrações foram elaboradas a partir de material herborizado, reidratado ou coletado em álcool 70\%. Utilizou-se uma câmara-clara acoplada a microscópio estereoscópico, as flores abertas foram comparadas com as fotos disponíveis em Costea (2007-onward).

As informações sobre distribuição geográfica, habitat e períodos de floração e frutificação dos táxons foram obtidas nas etiquetas dos exemplares examinados em herbários, nas observações em campo e na bibliografia.

\section{Resultados e Discussão}

O gênero Cuscuta está representado na Região Sul do Brasil por 15 táxons: C. boliviana Yunck., C. campestris Yunck., C. corniculata Engelm., C. epilinum Weihe, $C$. incurvata Progel, C. indecora Choisy var. neuropetala (Engelm.) Hitchc., C. obtusiflora Kunth, C. odorata Ruiz \& Pav., C. orbiculata Yunck., C. platyloba Progel, C. racemosa Mart., C. taimensis P.P.A. Ferreira \& Dettke, C. xanthochortos Mart. var. xanthochortos, C. xanthochortos var. carinata (Yunck.) Yunck. e C. xanthochortos var. lanceolata Yunck., sendo 13 ocorrentes no Estado do Paraná, oito em Santa Catarina e nove no Rio Grande do Sul (tabela 1). Cuscuta campestris e C. epilinum são exóticas, a primeira pode ser considerada naturalizada, foi coletada de forma espontânea em áreas úmidas, e a segunda foi registrada apenas em antigas culturas de linho, sendo a única espécie pertencente ao subgênero Cuscuta (caracterizado principalmente pelos estigmas cilíndricos), todas as outras espécies pertencem ao subgênero Grammica (caracterizado pelos estigmas globosos).

Até o momento, eram reconhecidos doze táxons de Cuscuta para a Região Sul do Brasil, de acordo com a literatura disponível (Yuncker 1922, 1923, 1932, Austin \& Costea 2008, Simão-Bianchini \& Ferreira 2010), destes, dez foram confirmados no presente estudo e dois foram excluídos: C. cristata Engelm., que foi citada por Simão Bianchini \& Ferreira (2010), porém, o voucher referido é da Argentina, da localidade "Paraná"; e C. partita Choisy, citada por Yuncker (1922), mas o voucher da localidade "Paranaguá" é do Estado do Piauí. Uma nova espécie foi descrita durante esta revisão, $C$. taimensis (Ferreira et al. 2014), quatro táxons foram incluídos para a área de estudo e foram confirmadas novas ocorrências para os Estados (tabela 1), sendo quatro para o Rio Grande do Sul (C. boliviana, C. indecora var. neuropetala, $C$. odorata e C. xanthochortos var. carinata), duas para Santa Catarina ( $C$. corniculata e C. xanthochortos var. xanthochortos) e nove para o Paraná (C. campestris, C. corniculata, C. epilinum, C. incurvata, C. obtusiflora, C. odorata, C. orbiculata e C. xanthochortos var. xanthochortos, C. xanthochortos var. lanceolata). 
Tabela 1. Táxons de Cuscuta L. citados para os Estados da Região Sul do Brasil em estudos anteriores e neste tratamento. (* exótica, ** naturalizada).

Table 1. Cuscuta L. taxa cited for the States of Southern Brazil in previous studies and in this treatment. (* exotic, ** naturalized).

\begin{tabular}{|c|c|c|c|c|c|c|}
\hline \multirow[b]{2}{*}{ Táxons } & \multicolumn{3}{|c|}{$\begin{array}{c}\text { Yuncker } \\
(1922,1923,1932), \\
\text { Austin \& Costea (2008), } \\
\text { Simão-Bianchini \& } \\
\text { Ferreira (2010) }\end{array}$} & \multicolumn{3}{|c|}{ Este tratamento } \\
\hline & PR & $\mathrm{SC}$ & RS & PR & $\mathrm{SC}$ & RS \\
\hline Cuscuta boliviana Yunck. & $\mathrm{X}$ & & & $\mathrm{X}$ & & $\mathrm{X}$ \\
\hline Cuscuta campestris Yunck.** ( $=$ C. pentagona Engelm. var. calycina Engelm.) & & $\mathrm{X}$ & & $\mathrm{X}$ & $\mathrm{X}$ & \\
\hline Cuscuta corniculata Engelm. & & & $\mathrm{X}$ & $\mathrm{X}$ & $\mathrm{X}$ & $\mathrm{X}$ \\
\hline Cuscuta cristata Engelm. & $\mathrm{X}$ & & & & & \\
\hline Cuscuta epilinum Weihe ex Boenn.* & & & & $\mathrm{X}$ & & \\
\hline Cuscuta incurvata Progel & & & & $\mathrm{X}$ & & \\
\hline Cuscuta indecora Choisy var. neuropetala (Engelm.) Hitchc. & $\mathrm{X}$ & & & $\mathrm{X}$ & & $\mathrm{X}$ \\
\hline Cuscuta obtusiflora Kunth & & $\mathrm{X}$ & $\mathrm{X}$ & $\mathrm{X}$ & $\mathrm{X}$ & \\
\hline Cuscuta odorata Ruiz \& Pav. & & $\mathrm{X}$ & & $\mathrm{X}$ & $\mathrm{X}$ & $\mathrm{X}$ \\
\hline Cuscuta orbiculata Yunck. & & & & $\mathrm{X}$ & & \\
\hline Cuscuta partita Choisy & $\mathrm{X}$ & & & & & \\
\hline Cuscuta platyloba Progel & $\mathrm{X}$ & $\mathrm{X}$ & $\mathrm{X}$ & $\mathrm{X}$ & $\mathrm{X}$ & $\mathrm{X}$ \\
\hline Cuscuta racemosa Mart. & $\mathrm{X}$ & $\mathrm{X}$ & $\mathrm{X}$ & $\mathrm{X}$ & $\mathrm{X}$ & $\mathrm{X}$ \\
\hline Cuscuta taimensis P.P.A. Ferreira \& Dettke & & & & & & $\mathrm{X}$ \\
\hline Cuscuta xanthochortos Mart. var. xanthochortos & & & $\mathrm{X}$ & $\mathrm{X}$ & $\mathrm{X}$ & $\mathrm{X}$ \\
\hline Cuscuta xanthochortos var. carinata (Yunck.) Yunck. & & $\mathrm{X}$ & & & $\mathrm{X}$ & $\mathrm{X}$ \\
\hline Cuscuta xanthochortos var. lanceolata Yunck. & & & & $\mathrm{X}$ & & \\
\hline Total & & & & 13 & 8 & 9 \\
\hline
\end{tabular}

Cuscuta xanthochortos var. lanceolata também constitui uma nova ocorrência para o Brasil. Foi excluída a ocorrência de C. obtusiflora para o RS, citada dor Simão-Bianchini \& Ferreira (2010), pois o material testemunho não foi encontrado. Todos os dados foram incluídos na Flora do Brasil 2020 (em construção).

Cuscuta L., Sp. Pl. 1: 124. 1753.

Espécie-tipo: Cuscuta europaea L., designado por Britton \& Brown (1913: 48).

Hemi ou holoparasitas volúveis, aclorofiladas, glabras, prendem-se ao hospedeiro por apressórios de onde emergem os haustórios. Ramos amarelos, alaranjados ou avermelhados. Áfilas ou com folhas escamiformes. Inflorescências em cimeiras laxas ou congestas a glomeruliformes. Brácteas lineares a ovadas. Flores bissexuais, actinomorfas, pentâmeras, raro tetrâmeras ou trímeras, cor branca, creme, amarela, rosada ou avermelhada. Laticíferos translúcidos globosos ou alongados visíveis ou não nas brácteas, cálice, corola, ovário/frutos. Cálice gamossépalo com lobos sobrepostos ou não, ápice obtuso a agudo, lisos ou carenados, sépalas unidas apenas na base. Corola gamopétala, campanulada, tubulosa ou urceolada, com lobos de ápice arredondado, obtuso a agudo, lisos ou carenados, eretos, patentes, inflexos ou reflexos. Estames exsertos ou inclusos; escamas infraestaminais fimbriadas ou não, soldadas na base do tubo da corola, às vezes ausentes. Ovário súpero, 2-locular com dois óvulos por lóculo; um ou dois estiletes apicais, às vezes ausentes; estigmas globosos, cilíndricos, cônicos ou clavados. Fruto indeiscente ou deiscente com deiscência circuncisa ou irregular. Sementes 1-4, 3-angulares ou dorsiventralmente comprimidas.

Chave para a identificação dos táxons do gênero Cuscuta na Região Sul do Brasil

1. Lobos do cálice sobrepostos

2. Cálice com apenas um dos lobos sobreposto basalmente

12. C. taimensis

2. Cálice com todos os lobos sobrepostos

3. Cálice mais curto que o tubo da corola

4. Lobos do cálice orbiculares, corola tubulosa

9. C. orbiculata

4. Lobos do cálice ovados a oblongos, corola campanulada

5. Corola sempre lisa, lobos com ápice arredondado, patente a reflexo .... 1. C. boliviana

5. Corola às vezes papilosa, lobos com ápice agudo, ereto a inflexo, às vezes carenado 3. C. corniculata

3. Cálice do mesmo tamanho ou mais longo que o tubo da corola

6. Cálice com ápice liso 
7. Lobos da corola com ápice obtuso, escamas infraestaminais orbiculares 8. C. odorata

7. Lobos da corola com ápice agudo, escamas infraestaminais oblongas 2. C. campestris

6. Cálice com ápice carenado

8. Lobos do cálice com ápice obtuso, lobos da corola ovado-oblongos .....

13b. C. xanthochortos var. carinata

8. Lobos do cálice com ápice agudo, lobos da corola ovado-triangulares ou ovado-lanceolados

9. Lobos do cálice ovados 13a. C. xanthochortos var. xanthochortos

9. Lobos do cálice ovado-lanceolados 13c. C. xanthochortos var. lanceolata

1. Lobos do cálice não sobrepostos

10. Margens dos lobos do cálice revolutas, estigmas cilíndricos 4. C. epilinum

10. Margens dos lobos do cálice não revolutas, estigmas globosos

11. Cálice do mesmo tamanho ou mais longo que o tubo da corola

12. Lobos da corola com ápice agudo, escamas infraestaminais oblongas, fimbriadas apenas no ápice 7. C. obtusiflora

12. Lobos da corola com ápice obtuso, raro agudo, escamas infraestaminais ovado-oblongas, fimbriadas desde a base 10. C. platyloba

11. Cálice mais curto que o tubo da corola

13. Lobos da corola triangulares, ápice agudo, escamas infraestaminais fimbriadas desde a porção mediana 6. C. indecora var. neuropetala

13. Lobos da corola ovados a ovado-oblongos, ápice obtuso, escamas infraestaminais fimbriadas desde a base

14. Ápice dos lobos da corola inflexo, escamas infraestaminais obovadas, fruto deiscente ..... 5. C. incurvata 14. Ápice dos lobos da corola reflexo, escamas infraestaminais oblongas, fruto indeiscente

11. C. racemosa

1. Cuscuta boliviana Yunck., Amer. J. Bot. 9: 565. 1922. Figura $1 \mathrm{a}-\mathrm{b}, 5$

Brácteas ovadas, ápice obtuso. Flores com 2,5-4 mm compr., cor branca ou creme; cálice mais curto que o tubo da corola, 2-2,4 mm compr., lobos ovados, sobrepostos, ápice obtuso; corola campanulada, lobos ovados a oblongos, ápice arredondado, patente a reflexo. Escamas infraestaminais obovadas a oblongas, fimbriadas desde a base; estigmas globosos. Laticíferos no cálice e na corola. Fruto deiscente; sementes com 1-1,5 mm compr.

Material examinado: BRASIL. PARANÁ: Curitiba, Parque Iguaçu, 20-III-2001, fl., J. Cordeiro \& E. Barbosa 1883 (MBM); Paranaguá, 25-X-1929, fl., F.C. Hoehne s.n. (SP 24476). RIO GRANDE DO SUL: Bom Jesus, Serra da Rocinha, 13-II-1947, fl., B. Rambo 35259 (PACA); Capão do Leão, Horto Botânico, 22-IV-1988, fl. e fr., J.A. Jarenkow \& J.L. Waechter 862 (PEL).

Ocorre na Bolívia (Yuncker 1932), na Argentina (Austin \& Costea 2008) e no Brasil, no Estado do Paraná (Flora do Brasil 2020 em construção), sendo aqui referida sua nova ocorrência para o Estado do Rio Grande do Sul. Na Região Sul, é encontrada nos Domínios Fitogeográficos Pampa e Mata Atlântica, em campos arbustivos e áreas úmidas. Floresce e frutifica principalmente de fevereiro a abril.

Semelhante à $C$. odorata, da qual difere pela relação entre o cálice e a corola e pela forma das escamas infraestaminais. Em $C$. odorata o cálice é do mesmo tamanho ou mais longo que o tubo da corola e as escamas infraestaminais são orbiculares, já em C. boliviana o cálice é mais curto que o tubo da corola e as escamas são obovadas a oblongas.

2. Cuscuta campestris Yunck., Mem. Torrey Bot. Club 18: 138.1932 = Cuscuta pentagona Engelm. var. calycina Engelm., Amer. J. Sci. 45: 76.1843 [1845].

Figura $1 \mathrm{c}-\mathrm{d}, 5$

Brácteas lanceoladas, ápice agudo. Flores com 2,5-3,5 $\mathrm{mm}$ compr., cor creme ou amarela, cálice mais longo que o tubo da corola, ca. $2 \mathrm{~mm}$ compr., lobos ovados a levemente orbiculares, sobrepostos, ápice obtuso; corola campanulada, lobos ovados a triangulares, ápice agudo, inflexo. Escamas infraestaminais oblongas, fimbriadas desde a base; estigmas globosos. Laticíferos nas brácteas, cálice e corola. Fruto indeiscente; sementes com 1,5 mm compr.

Material examinado: BRASIL. PARANÁ: Guarapuava, rio Coutinho, 15-III-1969, fl. e fr., R. Reitz \& M. Klein 17668 (FLOR, HBR). SANTA CATARINA: São Joaquim, divisa com o RS, 28²6’29.35’'S 4953'16.46”W, 15-I-2020, fl. e fr., P.P.A. Ferreira et al. s.n. (HAS 94427).

Ocorre no Canadá e nos Estados Unidos, sendo uma das espécies mais comuns nesses países e uma das ervas daninhas mais amplamente distribuídas no mundo, sendo encontrada na América do Sul, Europa, Ásia, África e Austrália (Costea et al. 2006). No Brasil, ocorre no Estados de Santa Catarina (Yuncker 1923) e São Paulo (Flora do Brasil 2020, em construção), sendo aqui referida para o Estado do Paraná. Na Região Sul, ocorre no Domínio Fitogeográfico Mata Atlântica, em áreas úmidas. Floresce e frutifica em janeiro e março. A espécie foi citada por Yuncker (1923) para Santa Catarina pelos exemplares G. Pabst 565 e $E$. Ule 487, porém não conseguimos localizá-los.

Semelhante à $C$. odorata que também possui o cálice mais longo que o tubo da corola e com os lobos sobrepostos, porém, em $C$. odorata a corola possui lobos com ápice obtuso, enquanto que em C. campestris, o ápice é agudo. Além disso, são características as escamas infraestaminais orbiculares de C. odorata, e em C. campestris estas são oblongas.

3. Cuscuta corniculata Engelm., Trans. Acad. Sci. St. Louis 1: 504. 1859.

Figura 1 e, 5

Brácteas ovadas, ápice obtuso. Flores com $3 \mathrm{~mm}$ compr., cor branca ou creme; cálice mais curto que o tubo da corola, ca. 1,5 mm compr., lobos ovados, sobrepostos, ápice obtuso; corola campanulada, às vezes levemente papilosa, lobos ovados, ápice agudo, ereto a inflexo, às vezes carenado. Escamas infraestaminais oblongas, fimbriadas desde a base; 

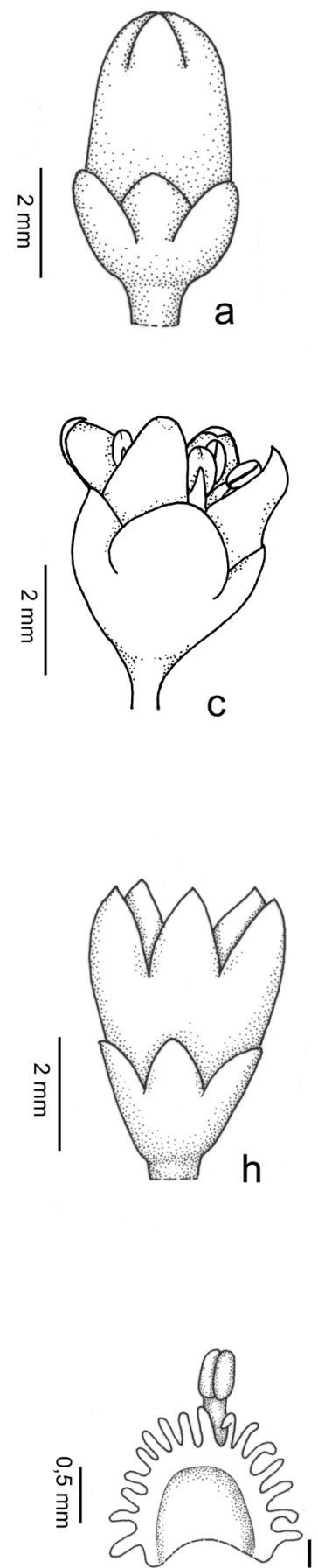
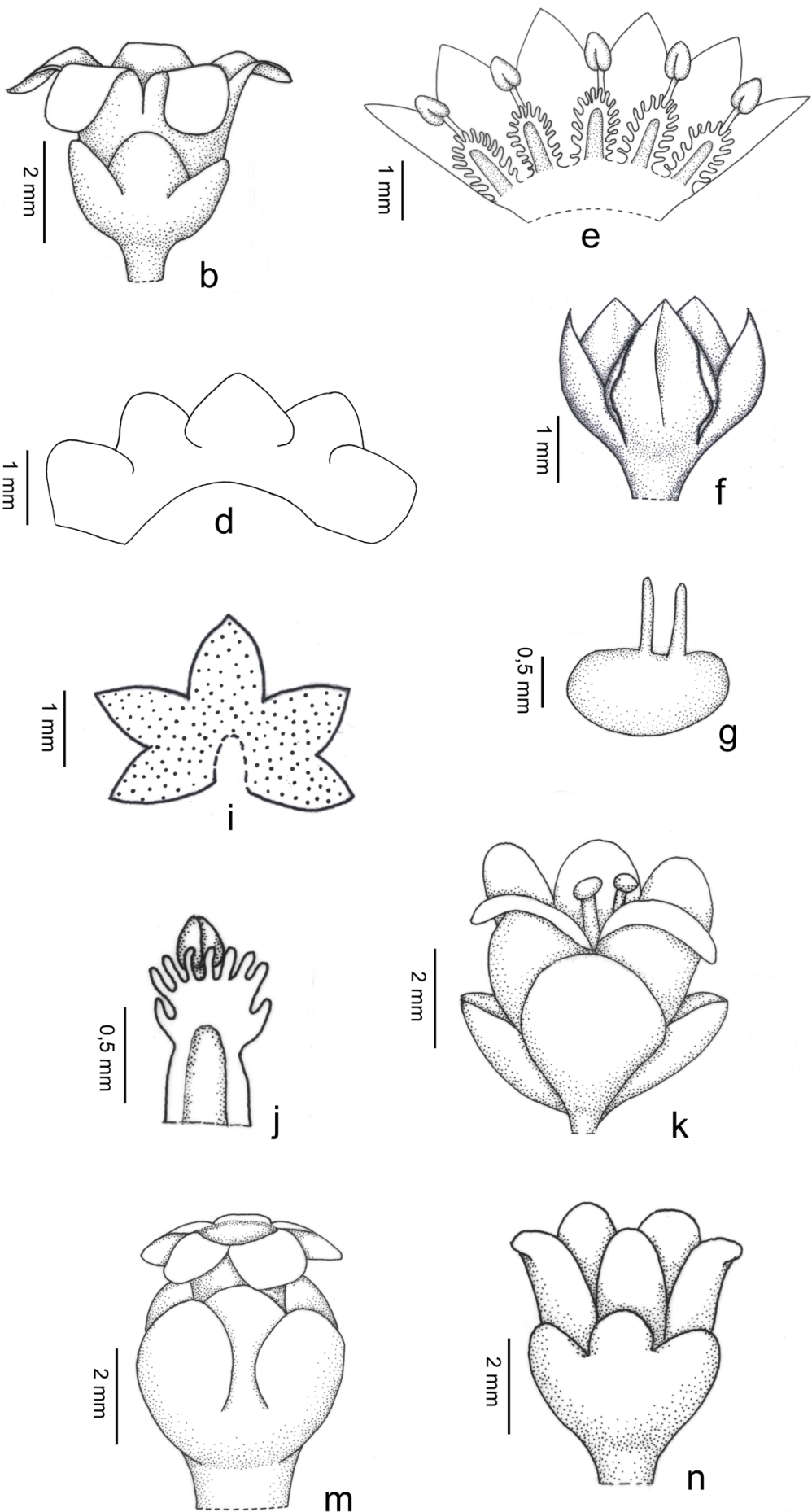

Figura 1. a-b. Cuscuta boliviana Yunck. a. Botão. b. Flor [J. Cordeiro \& E. Barbosa 1883 (MBM)]. c-d. Cuscuta campestris Yunck. c. Flor. d. Cálice aberto, vista dorsal [P.P.A. Ferreira et al. s.n. (HAS 94427)]. e. Cuscuta corniculata Engelm. e. Corola aberta, mostrando o androceu e as escamas infraestaminais [K. Hagelund 7579 (ICN)]. f-g. Cuscuta epilinum Weihe ex Boenn. f. Cálice. g. Gineceu, mostrando estigmas cilíndricos [M.J. Nowacki s.n. (MBM 80510)]. h. Cuscuta incurvata Progel. h. Flor [A.C. Cervi \& R.R. Silva 6263 (FLOR)]. i. Cuscuta indecora Choisy var. neuropetala (Engelm.) Hitchc. i. Cálice aberto, vista dorsal [M. Fleig 449 (ICN)]. j. Cuscuta obtusiflora Kunth. j. Estame e escama infraestaminal [G. Tessmann s.n. (MBM 265882)]. k-1. Cuscuta odorata Ruiz \& Pav. k. Flor. 1. Estame e escama infraestaminal [R. Reitz \& M. Klein 14950 (HBR)]. m. Cuscuta orbiculata Yunck. m. Flor [J. Lindeman \& H. Haas 5735 (MBM)]. n. Cuscuta platyloba Progel. n. Flor [B. Rambo 31772 (PACA)].

Figure 1. a-b. Cuscuta boliviana Yunck. a. Bud. b. Flower [J. Cordeiro \& E. Barbosa 1883 (MBM)]. c-d. Cuscuta campestris Yunck. c. Flower. d. Calyx, opened and flattened, dorsal view [P.P.A. Ferreira et al. s.n. (HAS 94427)]. e. Cuscuta corniculata Engelm. e. Corolla opened to expose androecium and infrastaminal scales [K. Hagelund 7579 (ICN)]. f-g. Cuscuta epilinum Weihe ex Boenn. f. Calyx. g. Gynoecium to expose cylindrical stigmas [M.J. Nowacki s.n. (MBM 80510)]. h. Cuscuta incurvata Progel. h. Flower [A.C. Cervi \& R.R. Silva 6263 (FLOR)]. i. Cuscuta indecora Choisy var. neuropetala (Engelm.) Hitchc. i. Calyx, opened and flattened, dorsal view [M. Fleig 449 (ICN)]. j. Cuscuta obtusiflora Kunth. j. Stamen and infrastaminal scale [G. Tessmann s.n. (MBM 265882)]. k-1. Cuscuta odorata Ruiz \& Pav. k. Flower. 1. Stamen and infrastaminal scale [R. Reitz \& M. Klein 14950 (HBR)]. m. Cuscuta orbiculata Yunck. m. Flower [J. Lindeman \& H. Haas 5735 (MBM)]. n. Cuscuta platyloba Progel. n. Flower [B. Rambo 31772 (PACA)]. 
estigmas globosos. Laticíferos nas brácteas, cálice e corola. Fruto deiscente; sementes com 1,5-2 mm compr.

Material examinado: BRASIL. Paraná: Porto Amazonas, Fazenda São Roque, 3-II-1976, fl., R. Kummrow 1073 (MBM). Rio GRANDE DO SUL: Pelotas, I.A.S., 9-I1954, fl., J.C. Sacco 84 (PEL, SPSF); Rio Grande, Ilha dos Marinheiros, 22-XI-2008, fl. e fr., U. Jacobi s.n. (HURG 004283); Torres, Lagoa Itapeva, 27-X-1985, fl., D.B. Falkenberg 2968 (FLOR); s.1., 5-I-1974, fl., K. Hagelund 7579 (ICN). SANTA CATARINA: Florianópolis, Alto Ribeirão, 20-XI-1969, fl. fr., M. Klein \& Bresolin 8486 (HBR); Ingleses, 21-I-1970, fl., M. Klein \& Bresolin 8565 (HBR); Siderópolis, 27-V-1996, fl., D.P. Cesconeto s.n. (CRI 5233).

Ocorre na Venezuela, Colômbia e Brasil (Yuncker 1932), nos Estados de Goiás, Bahia, Rio de Janeiro e Rio Grande do Sul (Flora do Brasil 2020 em construção), sendo aqui apresentada como nova ocorrência para o Estado de Santa Catarina e Paraná. Na Região Sul, é encontrada nos Domínios Fitogeográficos Pampa e Mata Atlântica, em borda de floresta de restinga e em campos limpos e arbustivos. Floresce e frutifica de outubro a maio.

Assemelha-se morfologicamente à $C$. xanthochortos var. carinata, pois ambas possuem lobos do cálice sobrepostos com ápice obtuso e corola com ápice agudo. Porém, C. xanthochortos var. carinata difere por apresentar as flores em geral um pouco maiores, com 3-4,5 mm de comprimento e cálice com ápice carenado, do mesmo tamanho ou mais longo que o tubo da corola ( $v s$. flores com até $3 \mathrm{~mm}$ de comprimento e cálice com lobos lisos, mais curto do que o tubo da corola em C. corniculata).

4. Cuscuta epilinum Weihe ex Boenn., Prodr. Fl. Monast. Westphal. 75. (1824).

Figura 1 f-g, 5

Flores com $3 \mathrm{~mm}$ compr., cor branca ou creme; cálice do mesmo tamanho que o tubo da corola, ca. $2 \mathrm{~mm}$ compr., lobos ovados, carenados, não sobrepostos, ápice agudo, margens revolutas; corola campanulada, lobos ovado-triangulares, ápice agudo ou obtuso. Escamas infraestaminais espatuladas, bífidas, fimbriadas apenas no ápice; estigmas cilíndricos. Fruto deiscente; sementes com 1,2 mm compr.

Material examinado: BRASIL. PARAnÁ: Curitiba, Bacacherí, 29-XII-1950, fl., M.J. Nowacki s.n. (MBM 80510); idem, 29-XII-1951, fl., M.J. Nowacki s.n. (MBM 4748).

Espécie nativa da Europa, Yuncker (1932) menciona que é comum em culturas de linho, sendo raramente encontrada parasitando outras plantas, e teria se dispersado a diversos países através das sementes. No Estado do Paraná, ocorre no Domínio Fitogeográfico Mata Atlântica, coletada em antigas culturas de linho, não possuindo registros recentes. Floresce em dezembro.

Muito distinta das outras espécies ocorrentes na Região Sul do Brasil, pois possui as margens dos lobos do cálice revolutas, as escamas infraestaminais bífidas e os estigmas cilíndricos.
5. Cuscuta incurvata Progel in Mart., Fl. Bras. 7: 379. 1871. Figura 1 h, 5

Brácteas lanceoladas, ápice agudo. Flores com 2-2,5 mm compr., cor branca ou creme; cálice mais curto que o tubo da corola, 1,7 mm compr., lobos ovados, não sobrepostos, ápice obtuso; corola campanulada, lobos ovados, reflexos, ápice obtuso, inflexo. Escamas infraestaminais obovadas, fimbriadas desde a base; estigmas globosos. Laticíferos nas brácteas e cálice. Fruto e sementes não vistos.

Material examinado: BRASIL. PARAná: Palmeira, Recanto dos Papagaios, 25-IV-1997, fl., A.C. Cervi \& R.R. Silva 6263 (MBM, FLOR); Lapa, Parque Estadual do Monge, 17-XII-2014, fl. e fr., E.D. Lozano et al. 2877 (MBM, SP).

Ocorre no Paraguai (Yuncker 1932) e no Brasil, no Estado de Minas Gerais (Flora do Brasil 2020 em construção), constituindo uma nova ocorrência para o Estado do Paraná, onde ocorre no Domínio Fitogeográfico Mata Atlântica, em áreas úmidas. Floresce em dezembro e em abril.

Dentre as espécies com lobos do cálice não sobrepostos, C. incurvata assemelha-se a C. obtusiflora, porém esta apresenta o cálice do mesmo tamanho que o tubo da corola, corola com ápice agudo e escamas infraestaminais oblongas, fimbriadas apenas no ápice, enquanto que em $C$. incurvata o cálice é mais curto que o tubo da corola, os lobos da corola são obtusos e as escamas infraestaminais são obovadas, fimbriadas desde a base. Outra espécie semelhante morfologicamente é $C$. racemosa, que difere principalmente pelo fruto indeiscente (vs. deiscente em C. incurvata). Yuncker (1932) observou frutos deiscentes e sementes com 1,5 mm de comprimento em C. incurvata.

6. Cuscuta indecora Choisy var. neuropetala (Engelm.) Hitchc., Contr. U.S. Natl. Herb. 9: 3: 549. 1896.

Figura 1 i, 5

Brácteas ovadas, papilosas, ápice obtuso. Flores com 2,5-4 mm compr., cor branca ou creme; cálice mais curto que o tubo da corola, 1,4 mm compr., lobos ovados, papilosos, não sobrepostos, ápice agudo ou obtuso; corola tubuloso-campanulada, lobos triangulares, eretos a inflexos, papilosos, ápice agudo. Escamas infraestaminais espatuladas, fimbriadas desde a porção mediana; estigmas globosos. Fruto indeiscente; sementes com 1,7 mm compr.

Material examinado: BRASIL. PARANÁ: Curitiba, Bacacherí, 18-XII-1951, fl., A. Frenzel s.n. (MBM 4750, NY 568357); idem, 18-XII-1951, fl., A. Frenzel s.n. (MBM 80506); Piraí do Sul, Fazenda Santa Ângela, XII-1952, fl. e fr., M.J. Nowacki s.n. (MBM 4749); idem, 3-XII-1952, fl. e fr., M.J. Nowacki s.n. (MBM 80507). RIO GRANDE DO SUL: São Sepé, Passo dos Freire, 13-I-1977, fl., M. Fleig 449 (ICN).

Ocorre na América do Norte, Central e do Sul (Yuncker 1932) e no Brasil (Engelmann 1859), nos Estados do Maranhão, Goiás, Minas Gerais e Paraná (Flora 
do Brasil 2020 em construção), constituindo uma nova ocorrência para o Estado do Rio Grande do Sul. Na Região Sul, é encontrada nos três Domínios Fitogeográficos, registrada para antigas culturas de alfafa, não possuindo registros recentes. Floresce e frutifica entre dezembro e janeiro.

Reconhecida pelas flores densamente papilosas, com os lobos do cálice não sobrepostos e pelos lobos da corola com ápice agudo. Outras espécies que apresentam flores papilosas são C. corniculata, C. racemosa e $C$. xanthochortos, mas C. corniculata e C. xanthochortos possuem lobos do cálice sobrepostos, e C. racemosa possui os lobos da corola com ápice obtuso.

Yuncker (1932) reconheceu cinco variedades para $C$. indecora: a variedade típica, com flores menores, $2-2,5 \mathrm{~mm}$ de comprimento (ocorrente nos EUA, México e América Central); C. indecora var. longisepala Yunck caracterizada pelo cálice com lobos lanceolados, acuminados, mais longos do que o tubo da corola (ocorrente nos EUA, México e na América do Sul); C. indecora var. integriuscula (Engelm.) Yunck, reconhecida pelo cálice com lobos triangulares, agudos, do mesmo tamanho que o tubo da corola, pelas escamas infraestaminais levemente fimbriadas, a partir da porção mediana, pelos estiletes mais curtos do que o ovário e pela cápsula translúcida (ocorrente na Argentina); C. indecora var. bifida Yunck., caracterizada pelas escamas infraestaminais bífidas (ocorrente nos EUA, México e na América do Sul) e C. indecora var. neuropetala que é citada por Simão-Bianchini e Ferreira (2010) como naturalizada no Brasil, porém, Engelmann (1859) e Yuncker (1932) já citavam esse táxon com distribuição ampla e parasitando diversos hospedeiros, incluindo culturas de alfafa.

7. Cuscuta obtusiflora Kunth, Nov. Gen. Sp. 3: 122. 1818. Figura $1 \mathrm{j}, 5$

Brácteas ovadas, ápice obtuso. Flores com $2 \mathrm{~mm}$ compr., cor branca ou creme; cálice do mesmo tamanho que o tubo da corola, 1-1,2 mm compr., lobos ovados, não sobrepostos, ápice obtuso; corola campanulada, lobos ovados, reflexos, ápice agudo. Escamas infraestaminais oblongas, fimbriadas apenas no ápice; estigmas globosos. Laticíferos nas brácteas, cálice, corola e ovário. Fruto e sementes não vistos.

Material examinado: BRASIL. Paraná: Ponta Grossa, Fazenda Lagoa Dourada, 17-II-1948, fl., G. Tessmann s.n. (MBM 265882). santa catarina: Imaruí, 17-XII-1946, fl., R. Reitz 1723 (MO).

Ocorre no Equador, Peru, Colômbia, Paraguai, Argentina e Brasil (Yuncker 1932), nos Estados do Mato Grosso, Minas Gerais, São Paulo e Santa Catarina (Flora do Brasil 2020 em construção), sendo aqui apresentada uma nova ocorrência para o Estado do Paraná. Na Região Sul, ocorre no Domínio Fitogeográfico Mata Atlântica, em campos arbustivos. Floresce em fevereiro.

Cuscuta obtusiflora assemelha-se morfologicamente à $C$. incurvata (já especificado nos comentários dessa espécie). São características de C. obtusiflora as escamas infraestaminais fimbriadas apenas no ápice. Yuncker (1932) descreve frutos indeiscentes e sementes com $1,5 \mathrm{~mm}$ de comprimento. A espécie foi citada por Simão-Bianchini \& Ferreira (2010) para o Rio Grande do Sul, porém, o material testemunho não foi localizado.

\section{Cuscuta odorata Ruiz \& Pav., Fl. Peruv. 1: 69. 1798}

Figura 1 k-1, 5

Brácteas ovadas, ápice obtuso. Flores com 4-6 mm compr., cor branca ou creme; cálice do mesmo tamanho ou mais longo que o tubo da corola, 2,4-2,6 mm compr., lobos ovado-orbiculares, sobrepostos, ápice obtuso; corola campanulada, lobos ovado-oblongos, eretos, ápice arredondado. Escamas infraestaminais orbiculares, fimbriadas desde a base; estigmas globosos. Laticíferos no cálice e corola. Fruto deiscente; sementes com 2-2,5 mm compr.

Material examinado: BRASIL. PARANÁ: Araucária, 15XII-1951, fl., M.J. Nowacki s.n. (MBM 4747); Paranaguá, Ipanema, 27-VIII-1969, fl. e fr., G. Hatschbach 22109 (MBM, MO, NY, S, UPCB); s.l., 7-VII-1947, fl. e fr., $G$. Hatschbach 743 (MBM). RIO GRANDE Do sUL: Augusto Pestana, caminho pra Ijuí, 10-IX-1974, fl., R.B. Medeiros s.n. (PEL 7944). SANTA CATARINA: Florianópolis, campus da UFSC, 10-VI-2010, fl., L.F. Lima 572 (ICN); Lages, caminho para Painel, 15-IV-1963, fl., R. Reitz \& M. Klein 14950 (HBR, R).

Ocorre no Peru, Equador, Bolívia, Chile, Argentina e Brasil (Yuncker 1932), nos Estados do Ceará, Rio de Janeiro, Minas Gerais e Santa Catarina (Flora do Brasil 2020 em construção), constituindo uma nova ocorrência para o Estado do Rio Grande do Sul. Na Região Sul, é encontrada no Domínio Fitogeográfico Mata Atlântica, em jardins urbanos, culturas de linho, áreas úmidas e borda de floresta de restinga. Floresce e frutifica de abril a dezembro.

Yuncker (1932) reconhece quatro variedades para C. odorata caracterizadas principalmente pela relação do comprimento dos lobos e do tubo da corola e pela forma do fruto, citando duas delas para o Brasil: a variedade típica, com ocorrência em Minas Gerais, e C. odorata var. botryoides Englem., com ocorrência no Sul do Brasil. As outras variedades ( $C$. odorata var. holwayana Yunck. e C. odorata var. squarrulosa Yunck.) ocorrem no Peru, Equador, Bolívia, Chile e Argentina. Aqui não consideramos variedades, pois as diferenças entre elas são tênues e não foi possível revisar o material de outras localidades para comparação.

Dentre as espécies com lobos do cálice sobrepostos, $C$. odorata é morfologicamente semelhante à $C$. boliviana e à C. campestris (cujas características já foram especificadas nos comentários dessas espécies).

9. Cuscuta orbiculata Yunck., Amer. J. Bot. 9: 572. 1923. Figura $1 \mathrm{~m}, 5$

Brácteas ovadas, ápice obtuso. Flores com 4-5 mm compr., cor branca ou creme; cálice mais curto que o tubo da corola, 3-3,6 mm compr., lobos orbiculares, sobrepostos, ápice arredondado; corola tubulosa, lobos ovado-oblongos, ápice arredondado, patente. Escamas infraestaminais oblongas, 
fimbriadas desde a base; estigmas globosos. Laticíferos nas brácteas, cálice, corola e ovário. Fruto e sementes não vistos. Material examinado: BRASIL. PARAnÁ: Matinhos, 20-VII-1967, fl., J. Lindeman \& H. Haas 5735 (MBM).

Endêmica do Brasil, encontrada nos Estados de Pernambuco e Goiás (Yuncker 1932, Flora do Brasil 2020 em construção), constituindo uma nova ocorrência para o Estado do Paraná. Na Região Sul, é encontrada no Domínio Fitogeográfico Mata Atlântica, em borda de floresta de restinga. Floresce em junho.

São características de $C$. orbiculata que a tornam distinta das outras espécies da Região Sul do Brasil, a corola tubulosa e o cálice mais curto que o tubo da corola, com lobos sobrepostos, orbiculares. Yuncker (1932) descreve frutos deiscentes e sementes com 1,5 mm de comprimento.

10. Cuscuta platyloba Progel in Mart., Fl. Bras. 7: 381. 1871. Figura 1 n, 5

Brácteas elípticas, ápice obtuso. Flores com 2-4 mm compr., cor branca ou creme; cálice do mesmo tamanho ou mais longo que o tubo da corola, 1,5-2 mm compr., lobos ovado-oblongos, não sobrepostos, ápice arredondado; corola campanulada, lobos ovado-oblongos, ápice obtuso, raro agudo, pouco reflexos. Escamas infraestaminais ovadooblongas, fimbriadas desde a base; estigmas globosos. Laticíferos no cálice e corola. Fruto indeiscente; sementes com 1,5-2 mm compr.

Material selecionado: BRASIL. PARAnÁ: Balsa Nova, Purunã, 14-XII-1979, fl. e fr., G. Hatschbach 42666 (MBM); Campina Grande do Sul, rio Taquari, 17-II-1957, fl., G. Hatschbach 3968 (PACA, MBM); Jaguariaíva, Parque Estadual do Cerrado, 30-V-1993, fl. e fr., M.C. Portes s.n. (MBM 313035), s.1., 23-VI-1910, fl., P. Dusén 10005 (S); Palmeira, Cercado, 14-II-2006, fl. e fr., E. Barbosa \& J. Cordeiro 1200 (MBM), Queimada, 30-III-1983, fl., $R$. Kummrow \& L. Bohs 2261 (MBM); Ponta Grossa, Buraco do Padre, 27-X-1995, fl., O.S. Ribas \& J. Cordeiro 898 (MBM), Parque Estadual Vila Velha, 13-XII-1965, fr., R. Reitz \& M. Klein 17555 (FLOR, HBR); São Mateus do Sul, Fazenda do Durgo, 8-I-1986, fl. e fr., J.T. Motta et al. 177 (MBM); Tamarana, região da Colônia penal Agrícola, 22-X-1986, F.C. Silva s.n. (FUEL 10743). RIO GRANDE DO SUL: Caxias do Sul, Vila Oliva, 8-II-1955, fl., B. Rambo 56755 (PACA); Mostardas, Praia do Bacopari, 17-XI-2007, fl., E. Pasini 224 (HUCS); São Francisco de Paula, Tainhas, Contendas, 17-III-1983, fl., J.R. Stehmann 110 (ICN); Torres, Itapeva, 28-X-1985, fl., J.R. Stehmann 755 (ICN). SANTA CATARINA: Blumenau, bairro Garcia, 30-VII-2007, fl., L. Sevegnani s.n. (FURB 4142); Brusque, Azambuja, 5-IV-1949, fl., R. Reitz 2990 (HBR); Florianópolis, Naufragados, s.d., fr., D.B. Falkenberg \& A. Zanin 2885 (FLOR); Itajaí, Escalvado, 12IV-1946, fl., R. Reitz 1597 (HBR), s.l., 10-VII-1975, fl., M. Klein 11184 (HBR); Lebon Régis, 6-III-1962, fl., M. Klein 3371 (HBR); Palhoça, campo do Maciambu, 5-II-1953, fl. e fr., R. Reitz 5545 (HBR); Sombrio, caminho para Araranguá, 7-VIII-1946, fl., B. Rambo 31772 (PACA).

Ocorre na Argentina, Uruguai e Brasil (Yuncker 1932), nos Estados do Pará, Mato Grosso, Goiás, Minas Gerais, Rio de Janeiro, São Paulo, Paraná, Santa Catarina e Rio Grande do Sul (Flora do Brasil 2020 em construção). Na Região Sul, é encontrada nos três Domínios Fitogeográficos, em borda de floresta de restinga e de galeria, campos limpos e arbustivos, afloramentos rochosos e áreas úmidas. Floresce e frutifica o ano todo, mais intensamente de outubro a março.

A espécie mais próxima morfologicamente à C. platyloba é $C$. racemosa, pois esta também apresenta cálice e corola com lobos obtusos e lobos do cálice não sobrepostos. Porém, $C$. platyloba possui o cálice do mesmo tamanho ou mais longo que o tubo da corola, enquanto que em C. racemosa o cálice é mais curto, além de ser levemente papiloso, o que não ocorre em C. platyloba. Outras espécies semelhantes são C. boliviana e $C$. odorata, ambas com os lobos do cálice e da corola obtusos ou arredondados como em C. platyloba, porém, essas possuem lobos do cálice sobrepostos.

11. Cuscuta racemosa Mart., Reise Bras. 1: 286. 1823. Figura 2 a-f, 4 a, 5

Brácteas elípticas, ápice obtuso. Flores com 3-3,5 $\mathrm{mm}$ compr., cor branca, creme, amarela ou avermelhada; cálice mais curto que o tubo da corola, 0,7-1 mm compr., lobos ovados a ovado-oblongos, levemente papilosos, não sobrepostos, ápice arredondado; corola tubulosocampanulada, lobos ovado-oblongos, ápice obtuso, reflexo. Escamas infraestaminais oblongas, fimbriadas desde a base; estigmas globosos. Laticíferos nas brácteas, cálice e corola. Fruto indeiscente; sementes com $2 \mathrm{~mm}$ compr.

Material selecionado: BRASIL. PARANÁ: Campo Largo, rio Papagaios, 14-III-1948, fl. e fr., G. Hatschbach 896 (MBM, SP); Campo Mourão, próximo à cidade, 28-XII2008, fl., G.A. Dettke 121 (ICN); Carambeí, rio São João, s.d., fr., R. Reitz \& M. Klein 17874 (FLOR, HBR, R); Curitiba, Recanto das Araucárias, 9-XI-1987, J.M. Silva \& J. Cordeiro 417 (HRB, INPA, MBM); Jaguariaíva, Parque Estadual do Cerrado, 3-II-2011, fr., G.A. Dettke \& P.P.A. Ferreira 562 (ICN); Lapa, Rio Passa Dois, 15-II-1967, fl. e fr., G. Hatschbach 15971 (MBM); Palmeira, rio Tibagi, 10-V-1964, fl. e fr., G. Hatschbach \& M. Joly 11259 (MBM); Pinhão, 16-III-1967, fl., J. Lindeman \& H. Haas 4937 (MBM); Piraí do Sul, Serra das Furnas, 30-III-1957, fl., G. Hatschbach 3972 (MBM); Ponta Grossa, Buraco do Padre, Desvio Ribas, 17-II-1911, fl., P. Dusén 11349 (S), Parque Estadual de Vila Velha, 13-XII-1969, fl., G. Hatschbach 23218 (MBM); São José dos Pinhais, Vale do Iguaçú, 22-XII-1950, fl. e fr., Tessmann \& A. Frenzel s.n. (MBM 80511); Tijucas do Sul, Ribeirão do Taboado, 7-IV-1958, fl. e fr., G. Hatschbach 4509 (MBM); Ubiratã, 20-IV-2004, fl., C. Rogério s.n. (HCF 1043); Sem município, rio Capão Grande, 5-III-1904, fl., $P$. Dusén 4006 (S). Rio GRANDE Do sul: Bom Jesus, Aparados da Serra, Fazenda Bernardo Velho, 29-XII-1946, fl., B. Rambo 34980 (PACA, S); Candelária, RST 287, km 132, 29॰40'48.8'S 5243'08.1'W, 22-III-2010, P.P.A. Ferreira et al. 390 (ICN); Porto Alegre, rua Carazinho esquina com João Abott, 5-V-2010, fl. e fr., P.P.A. Ferreira 402 (ICN); Quaraí, Passo da Guarda, 30¹8'45.8”S, 5604'27.0”W, 05-XII-2019, fl. fr., P.P.A Ferreira et al. (HAS 94428); São Francisco de Paula, Itaimbé, 17-I-1963, fl., A. Sehnem 8148 (PACA); Vacaria, 28-XII-1966, fl. e fr., J. Lindeman \& $H$. Haas 3750 (MBM). SANTA CATARINA: Caçador, $8 \mathrm{~km}$ ao Norte da cidade, 7-II-1957, fl., L.B. Smith \& M. Klein 10951 (HBR); Florianópolis, início da trilha para Naufragados, 29-II-1992, fl. e fr., D.B. Falkenberg 5619 (FLOR, PEL, ICN, MBM); 

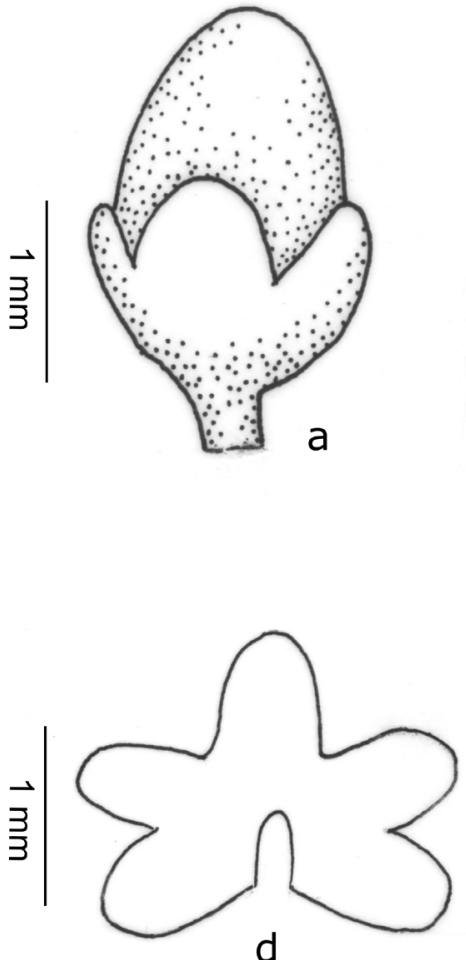

d
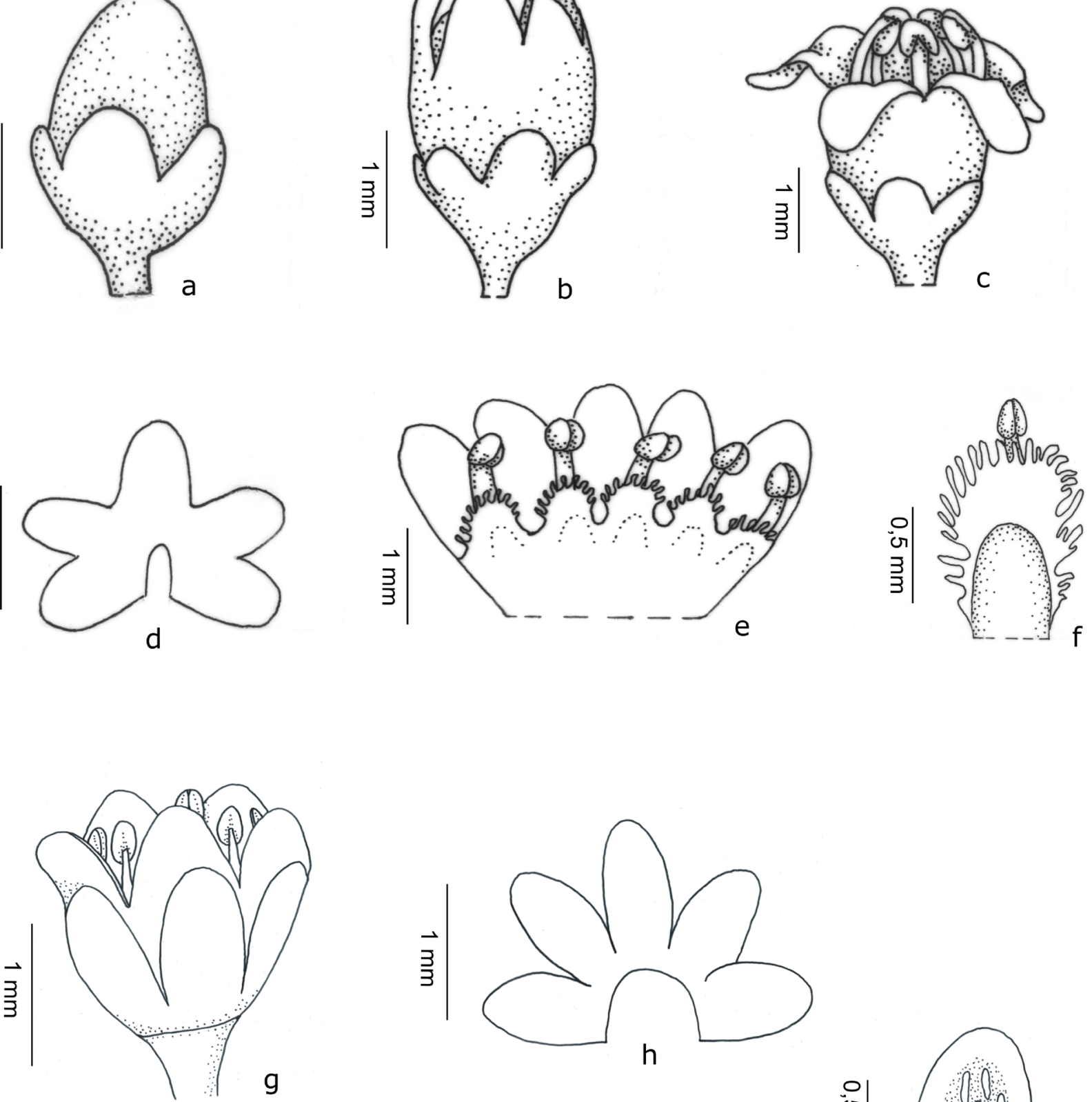

b

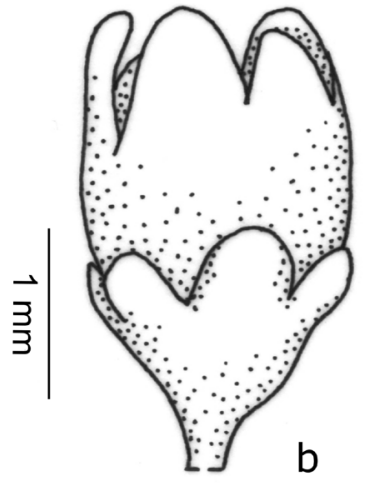

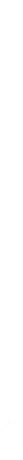


Guaraciaba, 3-I-1964, fl., R. Reitz \& M. Klein 16914 (HBR, R); Ilhota, 265' 55.1'S 48 52'18.5'W, 27-II-2011, fl. e fr., P.P.A. Ferreira et al. 698 (ICN); Mafra, 2-4 km ao Sul da cidade, 2-II-1957, fl., L.B. Smith \& M. Klein 10654 (HBR).

Endêmica do Brasil, ocorre nas Regiões Nordeste, Centro-Oeste, Sudeste e Sul (Yuncker 1932, Flora do Brasil 2020 em construção). Na Região Sul, é encontrada nos três Domínios Fitogeográficos, em afloramentos rochosos, jardins urbanos, campos limpos e arbustivos, culturas de linho, e em borda das florestas ombrófila mista e estacional. Floresce e frutifica de novembro a junho.

Cuscuta racemosa é semelhante morfologicamente à $C$. platyloba (características já especificadas nos comentários dessa espécie).

Yuncker (1932) reconhece três variedades para a espécie, a mais distinta, C. racemosa var. miniata (Mart.) Engelm., possui ramos papilosos e lobos do cálice sobrepostos, com ocorrência nas regiões Sudeste e CentroOeste. As outras duas variedades, C. racemosa Mart. var. racemosa e C. racemosa var. nuda Engelm., com ocorrência nas regiões Sudeste e Sul, são caracterizadas por mínimas diferenças no fruto. Não consideramos variedades, pois muitos espécimes examinados não continham frutos.

12. Cuscuta taimensis P.P.A. Ferreira \& Dettke, Brittonia 66(3): 269. 2014.

Figura 2 g-k, 5

Brácteas triangulares, ápice agudo ou obtuso, carenado. Flores com 2-2,5 cm compr., cor branca ou creme; cálice mais longo que o tubo da corola, 1,2 mm compr., lobos oblongos a elípticos, apenas um basalmente sobreposto, ápice arredondado; corola campanulada, lobos ovados, ápice arredondado, ereto. Escamas infraestaminais oblongas, fimbriadas desde a base; estigmas globosos. Laticíferos nas brácteas, cálice e corola. Fruto deiscente; sementes com 1,2-1,5 mm compr.

Material examinado: BRASIL. RIO GRANDE Do SUL: Rio Grande, Estação Ecológica do Taim, 3-V-1986, fl. e fr., Viana 12 (ICN), Lagoa do Jacaré, 3-V-1986, fl. e fr., J.A. Jarenkow et al. 301 (PEL).

Ocorre no Uruguai e no Brasil, no Estado do Rio Grande do Sul (Ferreira et al. 2014), no Domínio Fitogeográfico Pampa, em campos arbustivos e áreas úmidas. Floresce e frutifica em maio.

Cuscuta taimensis pode ser reconhecida por possuir apenas um lobo do cálice basalmente sobreposto, cálice e corola com ápices obtusos, além do cálice mais longo do que o tubo da corola e fruto deiscente. Próxima morfologicamente à $C$. platyloba, que difere por possuir os lobos do cálice não sobrepostos e o fruto indeiscente.

13a. Cuscuta xanthochortos Mart. var. xanthochortos, Trans. Acad. Sci. St. Louis 1: 486. 1859.

Figura 3 a-c, 4 b-d, 5

Brácteas ovadas, ápice agudo. Flores com 2-4,5 mm compr., cor branca ou creme; cálice do mesmo tamanho ou mais longo que o tubo da corola, 1,5-2 mm compr., lobos ovados, sobrepostos, ápice agudo, carenado; corola campanulada, às vezes papilosa, lobos ovado-triangulares, ápice agudo, inflexo, carenado ou liso. Escamas infraestaminais oblongas, fimbriadas a partir da porção mediana ou um pouco abaixo; estigmas globosos. Laticíferos nas brácteas, cálice, corola e ovário. Fruto deiscente; sementes com 1,5-2 mm compr.

Material selecionado: BRASIL. PARANÁ: Jaguariaíva, margem do rio das Mortes, 16-XII-2010, fl., J.R.V. Iganci et al. 736 (ICN); Palmas, campos de Palmas, s.d., fl. e fr., G. Hatschbach 28288 (MBM); Ponta Grossa, Buraco do Padre, 24.XI.1999, fl., C.B. Poliquesi et al. 648 (MBM). Rio Grande do Sul: Alegrete, Cerro do Tigre, 6.I.2007, fl., E. Freitas 78 (ICN); Arroio dos Ratos, s.1., 20-V-1995, fl., R.M. Senna s.n. (ICN 117411); Caçapava do Sul, Pedra do Segredo, 29-XI-2002, fl., V.F. Kinupp \& B.E. Irgang 2503 (ICN); Cachoeira do Sul, 6-I-1902, fl., G.O.A. Malme 1002 (S); Caxias do Sul, Vila Oliva, 4-I-1946, fl., B. Rambo 31042 (PACA); Encruzilhada do Sul, $28 \mathrm{~km}$ antes da cidade, 16-XI-1978, fl., J. Mattos et al. 19038 (HAS); Guaíba, Fazenda São Maximiano, 10.XII.2002, fl., A.A. Schneider 10 (ICN); Lavras do Sul, Cabanha Macanudo, Rincão do Inferno, 3051'25.5'S 5342'41.7' 'W, 13-I-2010, fl. e fr., P.P.A.Ferreira et al. 321 (ICN); Porto Alegre, Morro São Pedro, 11.II.2006, fl., R. Setubal \& J. Cabral 340 (ICN); Quaraí, Butiazal do Quatepe, 30²4'05.3'S 56¹1'18.5”W, 9.II.2012, fl. e fr., P.P.A. Ferreira et al. 868 (ICN); Rio Pardo, Dois Cerros, 12-V-1978, fl., J. Mattos \& O. Camargo 18732 (HAS); Rosário do Sul, beira da Sanga da Areia, 18-II-1990, fl., D. Falkenberg 5303 (ICN, FLOR); Santana da Boa Vista, Fazenda Passo da Chácara, 30-III-1975, fl., A. Sehnem 14607 (PACA); São Vicente do Sul, Cerro Loreto, XII-1985, fl., $M$. Sobral \& J. Marchiori 4563 (ICN); Taquari, Cerro Pelado, 4-I-1996, fl., M. Sobral et al. s.n. (ICN 111081); Torres, Butiazal, 17-I-1980, fl., J.F. Prado s.n. (ICN 47313); Trindade do Sul, 28-I-2009, fl., M. Zanotto 87 (HUCS); Tupanciretã, Ijuizinho, 30-I-1940, fl., B. Rambo 9984 (PACA); Vacaria, 7 km em direção a Bom Jesus, 23-XI-1977, fl., J. Mattos \& N. Mattos 16704 (HAS). SAnta Catarina: Campos Novos, 20-XII-1962, fl., R. Reitz \& M. Klein 14272 (HBR); Chapecó, Campo Erê, 24-I-1952, fl., R. Reitz 4524 (HBR); Itajaí, 12IV-1946, fl., R. Reitz 1597 (S); Ponte Serrada, Campos de Palmas, s.d., fl. e fr., G. Hatschbach 28288 (MBM).

Ocorre na Argentina, Uruguai e Brasil, no Estado do Rio Grande do Sul (Yuncker 1932), constituindo uma nova ocorrência para os Estados de Santa Catarina e Paraná. Na Região Sul, é encontrada nos três Domínios Fitogeográficos, em campos limpos, arbustivos, áreas úmidas, afloramentos rochosos e em borda da floresta estacional. Floresce e frutifica de novembro a maio.

Espécie caracterizada pelos lobos do cálice e da corola com ápices carenados. Semelhante à $C$. corniculata que, às vezes, apresenta lobos da corola carenados e papilosos, porém, o cálice é mais curto que o tubo da corola e os lobos são lisos com ápice obtuso (vs. do mesmo tamanho ou mais longo, carenados e agudos em C. xanthochortos var. xanthochortos).

13b. Cuscuta xanthochortos var. carinata (Yunck.) Yunck., Mem. Torrey Bot. Club 18: 205. 1932.

Figura 3 d-e, 5

Difere da variedade típica pelos lobos do cálice com ápice obtuso e pelos lobos da corola ovado-oblongos. 

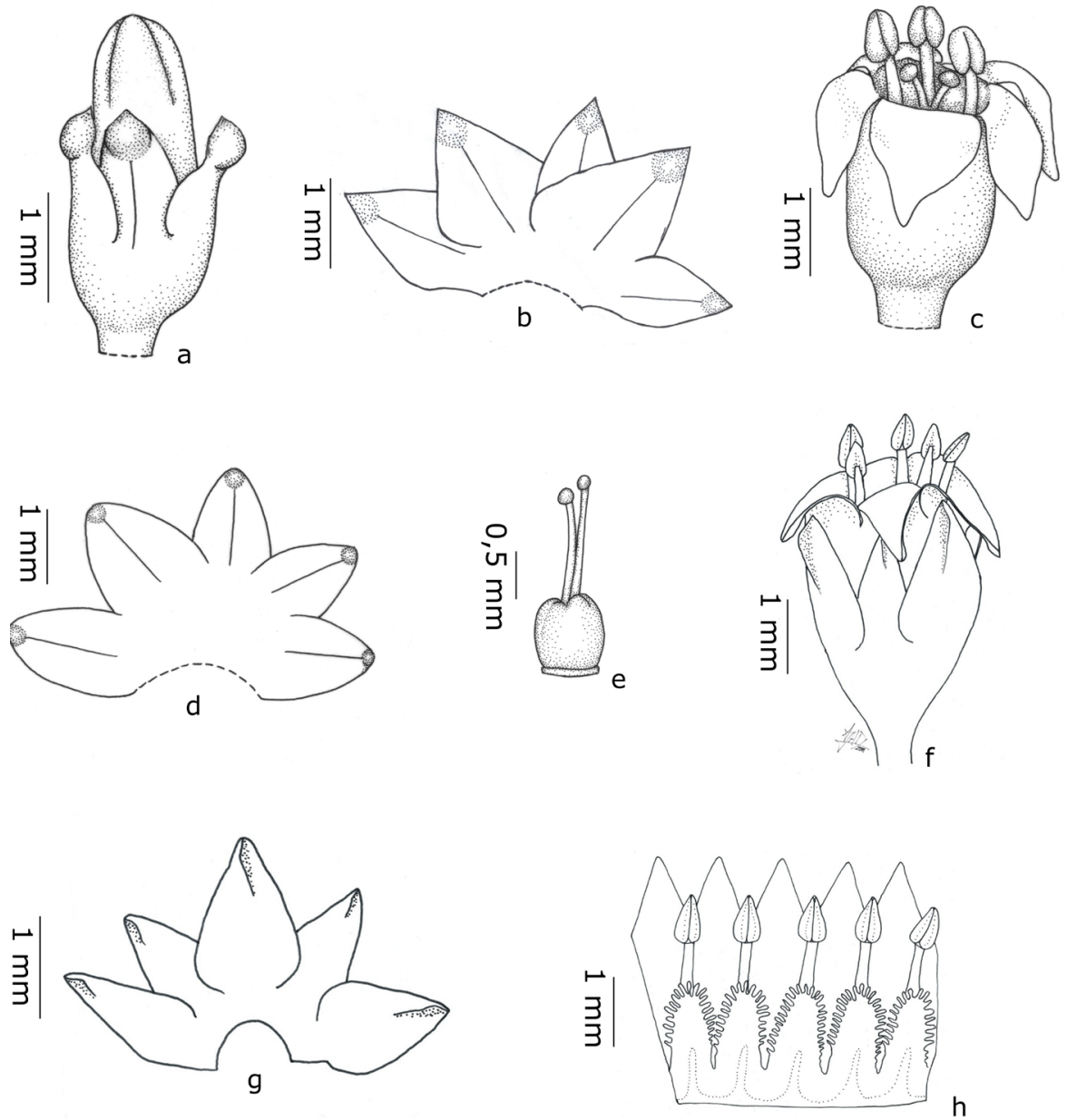

Figura 3. a-c. Cuscuta xanthochortos Mart. var. xanthochortos. a. Botão. b. Cálice aberto, vista dorsal. c. Corola, androceu e gineceu [P.P.A.Ferreira et al. 321 (ICN)]. d-e. Cuscuta xanthochortos var. carinata (Yunck.) Yunck. d. Cálice aberto, vista dorsal. e. Gineceu [Schultz 122 (ICN)]. f-h. Cuscuta xanthochortos var. lanceolata Yunck. f. Flor. g. Cálice aberto, vista dorsal. h. Corola aberta, mostrando $\mathrm{o}$ androceu e as escamas infraestaminais [G. Hatschbach \& A.C. Cervi 48864 (MBM)].

Figure 3. a-c. Cuscuta xanthochortos Mart. var. xanthochortos. a. Bud. b. Calyx, opened and flattened, dorsal view. c. Corolla, androecium and gynoecium [P.P.A.Ferreira et al. 321 (ICN)]. d-e. Cuscuta xanthochortos var. carinata (Yunck.) Yunck. d. Calyx, opened and flattened, dorsal view. e. Gynoecium [Schultz 122 (ICN)]. f-h. Cuscuta xanthochortos var. lanceolata Yunck. f. Flower. g. Calyx, opened and flattened, dorsal view. h. Corolla opened to expose androecium and infrastaminal scales [G. Hatschbach \& A.C. Cervi 48864 (MBM)].
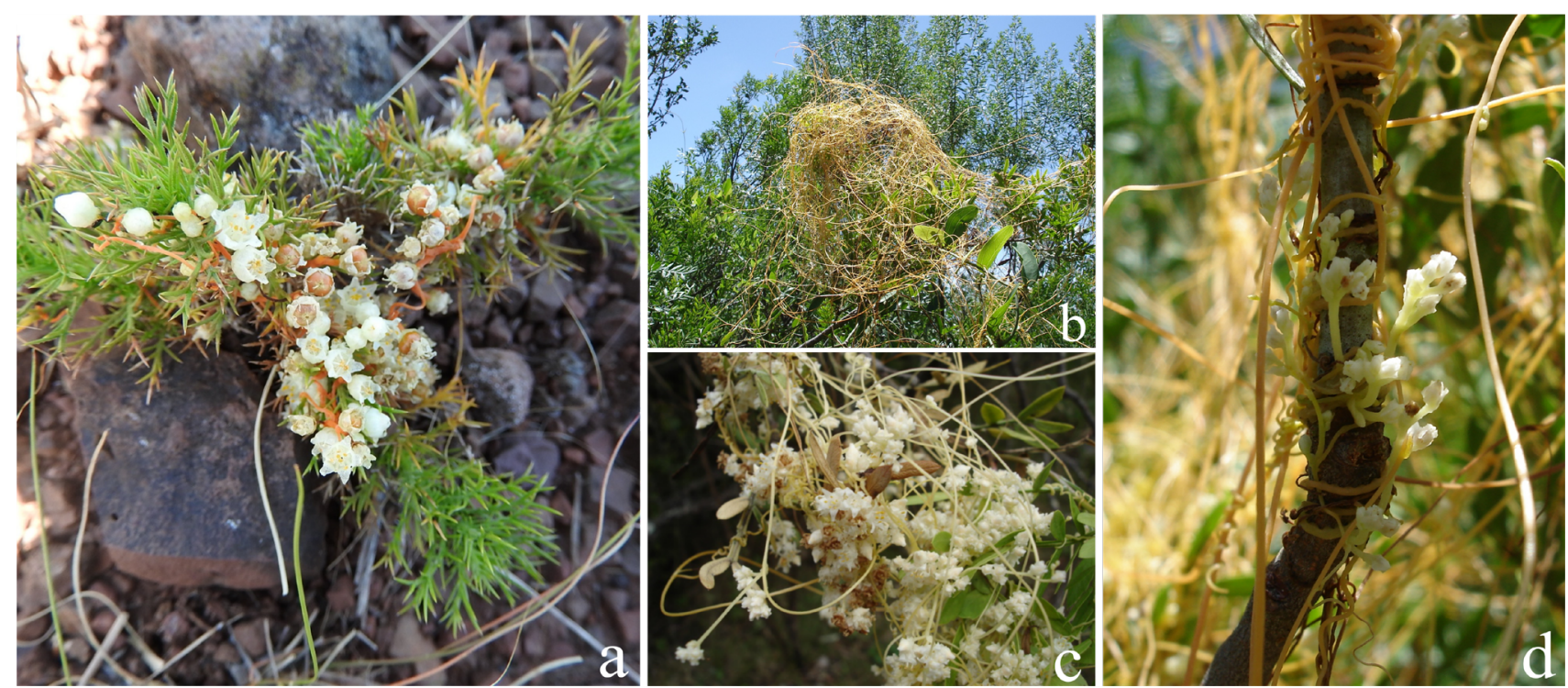

Figura 4. a. Cuscuta racemosa Mart. Hábito. b-d. Cuscuta xanthochortos Mart. var. xanthochortos. b. Hábito. c. Ramos com flores e frutos. d. Ramos, mostrando os haustórios Fotos: Priscila Ferreira.

Figure 4. a. Cuscuta racemosa Mart. Habit. b-d. Cuscuta xanthochortos Mart. var. xanthochortos. b. Habit. c. Branches with flowers and fruits. d. Branches expose haustoria. Photos: Priscila Ferreira 

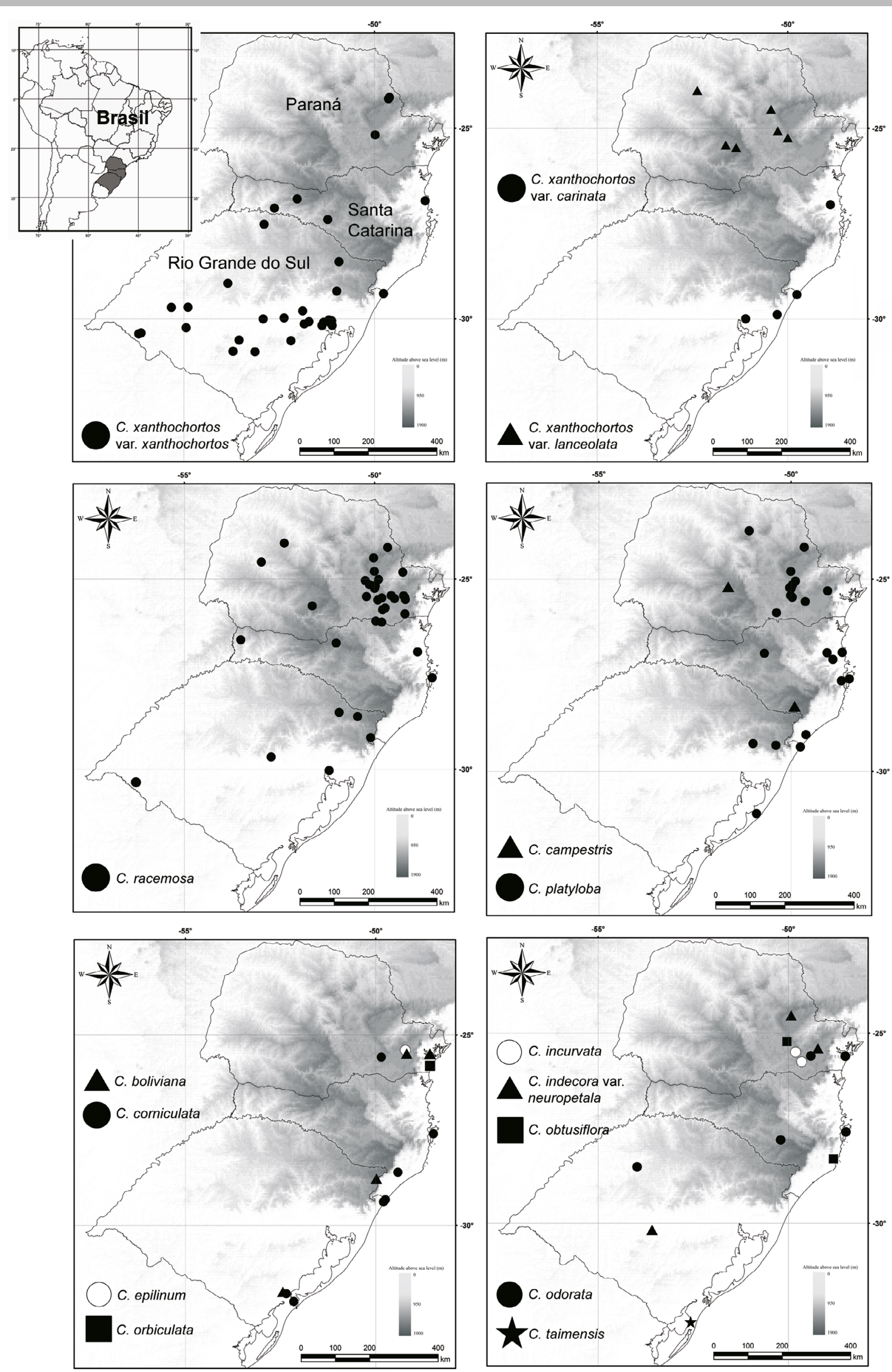

Figura 5. Mapas de distribuição das espécies de Cuscuta L. na Região Sul do Brasil. Figure 5. Distribution maps of Cuscuta L. species in Southern Brazil. 
Material examinado: BRASIL. SANTA CATARINA: Brusque, 5-IV-1949, fl., R. Reitz 2990 (S). RIO GRANDE DO SUL: Osório, Lagoa das Malvas, 19-I-1951, fl. e fr., A. Sehnem s.n. (PACA 5597); Porto Alegre, esquina da Av. Princesa Isabel com a Rua Gomes Jardim, 3002'51.37'S 51 ${ }^{\circ} 12$ '23.50”W, 3-I-2018, fl. fr., P.P.A. Ferreira s.n. (HAS 94072); Torres, Itapeva, Lagoa dos Simões, 25-I-1941, fl., Schultz 122 (ICN).

Ocorre no Paraguai, Argentina (Yuncker 1932) e Brasil, no Estado de Santa Catarina (Austin \& Costea 2008), constituindo uma nova ocorrência para o Estado do Rio Grande do Sul. Na Região Sul, ocorre nos Domínios Fitogeográficos Mata Atlântica e Pampa, em áreas úmidas e jardins urbanos. Floresce e frutifica de janeiro a abril.

Próxima morfologicamente à $C$. corniculata (características já discutidas nos comentários dessa espécie).

13c. Cuscuta xanthochortos var. lanceolata Yunck., Amer. J. Bot. 9: 568. 1922.

Figura $3 \mathrm{f}-\mathrm{h}, 5$

Difere da variedade típica por apresentar os lobos do cálice e da corola ovado-lanceolados.

Material examinado: BRASIL. PARANÁ: Campo Mourão, 8-XII-1965, fl. e fr., G. Hatschbach et al. 13277 (MBM), s.l., 14-X-1965, fl. e fr., G. Hatschbach 12987 (MBM), s.l., 20-XI-2003, fl., M.G. Caxambu 204 (HCF); Guarapuava, Fazenda Campo Real, 7-II-1969, fl., G. Hatschbach 21023 (MBM), Posto Agropecuário, 29-I-1968, fl., G. Hatschbach 18348 (MBM), BR 277, 22-I-1998, fl. e fr., E. Barbosa et al. 114 (MBM); Ponta Grossa, Fazenda Cambiju, 28-I-1985, fl., G. Hatschbach \& A.C. Cervi 48864 (MBM), Parque Estadual de Vila Velha, 15-I-1987, fl. e fr., A. Krapovickas \& C.L. Cristóbal 40860 (MBM), idem, 21-XII-1962, fl., G. Hatschbach 9607 (MBM), idem, 23-XI-1963, fl. e fr., $E$. Pereira \& G. Hatschbach 8103 (MBM); Tibagi, Fazenda Monte Alegre, 14-XI-1952, fl., G. Hatschbach 2855 (MBM).

Ocorre no Paraguai (Yuncker 1932) e na Argentina (Austin \& Costea 2008), constituindo aqui como uma nova ocorrência para o Brasil, no Estado do Paraná, onde é encontrada nos Domínios Fitogeográficos Mata Atlântica e Cerrado, principalmente em campos limpos e arbustivos. Floresce e frutifica de outubro a fevereiro.

Distinta das outras espécies ocorrentes na Região Sul, por apresentar os lobos do cálice ovado-triangulares, carenados.

\section{Agradecimentos}

Aos Curadores e funcionários dos herbários nacionais e internacionais, pelo empréstimo, doação, envio de fotografias das exsicatas e/ou permissão para consulta das coleções. Ao Dr. Mihai Costea, por todas as valiosas sugestões e à doutoranda Simone Soares da Silva pelo auxílio com o material do Herbário SP. À CAPES, pela bolsa de Doutorado PROTAX concedida à primeira Autora e ao $\mathrm{CNPq}$, pela bolsa de Doutorado concedida à segunda autora e pelas Bolsas de Produtividade em Pesquisa concedidas à terceira $(\mathrm{CNPq}-311738 / 2016-8)$ e quarta autoras. Ao programa de Pós-Graduação em Botânica da Universidade Federal do Rio Grande do Sul, onde este trabalho foi desenvolvido.

\section{Conflitos de interesse}

Os autores declaram que não há conflitos de interesse.

\section{Contribuição dos Autores}

Priscila Porto Alegre Ferreira e Greta Aline Dettke: coleta e identificação das espécies, revisão de Herbários, caracterização morfológica das espécies e dados adicionais, redação do texto.

Greta Aline Dettke: ilustrações e mapas.

Rosangela Simão-Bianchini: revisão de Herbários, caracterização morfológica das espécies e dados adicionais, revisão do texto.

Silvia Teresinha Sfoggia Miotto: orientação, supervisão, revisão do texto.

\section{Literatura citada}

Ahmad, A., Tandon, S., Xuan, T.D. \& Nooreen, Z. 2017. A Review on Phytoconstituents and Biological activities of Cuscuta species. Biomedicine \& Pharmacotherapy 92: 772-795.

Alencar, J., Cordeiro, W.P.F.S., Staples, G. \& Buril, M.T. 2019. Convolvulaceae no Parque Nacional de Sete Cidades, Estado do Piaú, Brasil. Hoehnea 46: e992018.

Austin, D.F. 1998. Parallel and Convergent Evolution in the Convolvulaceae. In: P. Mathews \& M. Sivadasan (ed.). Diversity and Taxonomy of Tropical Flowering Plants. Mentor Books, Calicut, pp. 201-234.

Austin, D.F. \& Costea, M. 2008. Cuscuta L. In: F.O. Zuloaga, O. Morrone \& M.J. Belgrano (eds.). Catálogo de las plantas vasculares del Cono Sur (Argentina, Sur de Brasil, Chile, Paraguay y Uruguay). Monographs in Systematic Botany from the Missouri Botanical Garden 107, Saint Louis, pp. 1942-1947.

Bandeira, A.N.T, Bautista, H.P., Buril, M.T. \& Melo, J.I.M. 2019. Convolvulaceae no Parque Ecológico Engenheiro Ávidos, Alto Sertão Paraibano, Nordeste do Brasil. Rodriguésia 70.

Britton, N.L. \& Brown A. 1913. An illustrated flora of the northern United States and Canada, 2 ed., part 3. Charles Scribner's Sons, New York.

Costea, M. (2007-onward). Digital Atlas of Cuscuta (Convolvulaceae) Wilfrid Laurier University, Ontario. Disponível em https://specialprojects.wlu.ca/herbarium/ digital-atlas-of-cuscuta-convolvulaceae/ (acesso em 11-XI-2020).

Costea, M., Nesom, G.L. \& Stefanovic, S. 2006. Taxonomy of the Cuscuta pentagona complex (Convolvulaceae) in North America. Sida 22: 151-175.

Costea, M. \& S. Stefanovic. 2009. Cuscuta jepsonii (Convolvulaceae), an invasive weed or an extinct endemic? American Journal of Botany 96: 1744-1750. 
Costea, M., Felger, R.S., Austin, D.F., Devender, T.R. \& Sanchez-Escalante, J.J. 2012. Convolvulaceae of Sonora, Mexico II: Cuscuta. Journal of the Botanical Research Institute of Texas 6: 529-550.

Costea, M., García, M.A. \& Stefanović, S. 2015. A phylogenetically based infrageneric classification of the parasitic plant genus Cuscuta (dodders, Convolvulaceae). Systematic Botany 40(1): 269-285.

CRIA - Centro de Referência em Informação Ambiental speciesLink. Disponível em http://inct.splink.org.br/ (acesso em 11-XI-2020).

Cronquist, A. 1981. An Integrated System of Classification of Flowering Plants. New York Botanical Garden, New York.

Cronquist, A. 1988. The evolution and classification of flowering plants. 2 ed. New York Botanical Garden, New York.

Cruz Neto, O., Leal, .I.R, Santos, J.C. \& Lopes, A.V. 2017. A holoparasitic plant severely reduces the vegetative and reproductive performance of its host plant in the Caatinga, a Brazilian seasonally dry forest. Acta Botanica Brasilica 31:147-152.

Donnapee, S., Li, J., Yang, X., Ge, A., Donkor, .P.O, Gao, X. \& Chang, Y. 2014. Cuscuta chinensis Lam.: A systematic review on ethnopharmacology, phytochemistry and pharmacology of an important traditional herbal medicine. Journal of ethnopharmacology 157: 292-308.

Engelmann, G. 1859. Systematic arrangement of the species of the genus Cuscuta with critical remarks on old species and descriptions of new ones. Transactions of the Academy of Science of St. Louis 1: 453-523.

Feinbrun, N. 1970. A taxonomic review of European Cuscutae. Israel Journal of Botany 19: 16-29.

Ferreira, P.P.A., Dettke, G.A., Waechter, J.L. \& Miotto, S.T.S. 2014. Cuscuta taimensis (Convolvulaceae), a new species from South America. Brittonia 66: 269-273.

Flora do Brasil 2020 em construção. Jardim Botânico do Rio de Janeiro. Disponível em http://floradobrasil.jbrj. gov.br/ (acesso em 11-XI-2020).

García, M. A. \& Martín, M.P. 2007. Phylogeny of Cuscuta subgenus Cuscuta (Convolvulaceae) based on nrDNA ITS and chloroplast trnL intron sequences. Systematic Botany 32: 899-916.

García, M. A., Costea, M., Kuzmina, M. \& Stefanović, S. 2014. Phylogeny, character evolution, and biogeography of Cuscuta (dodders; Convolvulaceae) inferred from coding plastid and nuclear sequences. American Journal of Botany 101: 670-690.

Hunziker,A. T. 1949. Las especies de Cuscuta (Convolvulaceae) de Argentina y Uruguay. Revista de la Facultad de Ciencias Exactas Fisicas y Naturales 12: 1101-1202.

Hunziker,A. T. 1950. Las especies de Cuscuta (Convolvulaceae) de Argentina y Uruguay (continuación). Revista de la Facultad de Ciencias Exactas Fisicas y Naturales 13: 177-251.
IBGE - Instituto Brasileiro de Geografia e Estatística. Disponível em www.ibge.gov.br (acesso em 11-XI2020).

JBRJ - Instituto de Pesquisas Jardim Botânico do Rio de Janeiro. Jabot - Banco de Dados da Flora Brasileira. Disponível em http://jabot.jbrj.gov.br/ (acesso em 11-XI-200).

Lanini, W., Kogan, M. 2005. Biology and management of Cuscuta in crops. Ciencia e Investigación Agraria 32:127-141.

Múlgura, M.E. 1979. Cuscutaceae. In: A. Burkart (ed.). Flora Ilustrada de Entre Ríos. INTA, Buenos Aires, v. 5, pp. 195-203.

Nepomuceno,S.C.2019. OGênero Cuscuta L. (Convolvulaceae) no Nordeste Brasileiro. Dissertação de Mestrado, Universidade Federal Rural de Pernambuco, Pernambuco.

Nickrent, D.L. 2020. Parasitic angiosperms: how often and how many? Taxon 69: 5-27.

Press, M.C. \& Phoenix, G.K. 2005. Impacts of parasitic plants on natural communities. New Phytologist 166: 737-751.

Progel, A. 1871. Cuscutaceae. In: Martius, C.F.P. (ed.). Flora Brasiliensis. Typographia Regia, Monachii, v. 7, pp. 371-390.

Reflora. Herbário Virtual. Disponível em http://floradobrasil. jbrj.gov.br/reflora/herbarioVirtual/ConsultaPublicoHVUC/ ConsultaPublicoHVUC.do (acesso em 11-XI-2020).

Riviere, S., Clayson, C., Dockstader, K., Wright, M.A.R. \& Costea, M. 2013. To attract or to repel? Diversity, evolution and role of the "most peculiar organ" in the Cuscuta flower (dodder, Convolvulaceae)-the infrastaminal scales. Plant Systematic and Evolution 299: 529-552.

Silva, S.S. 2020. Cuscuta L. (Convolvulaceae) da Região Sudeste do Brasil. Dissertação de Mestrado. Instituto de Botânica, São Paulo.

Simão-Bianchini, R. \& Pirani, J.R. 1997. Flora da Serra do Cipó, Minas Gerais: Convolvulaceae. Boletim de Botânica da Universidade de São Paulo 16: 125-149.

Simão-Bianchini, R. \& Ferreira, P.P.A. 2010. Convolvulaceae. In: R.C. Forzza et al. (eds.). Catálogo de Plantas e Fungos do Brasil, v.2., Andrea Jakobsson Estúdio: Instituto de Pesquisas Jardim Botânico do Rio de Janeiro, Rio de Janeiro, pp. 882-894.

Simão-Bianchini, R; Vasconcelos, L.V. \& Pastore, M. 2016. Flora of the cangas of the Serra dos Carajás, Pará, Brazil: Convolvulaceae. Rodriguésia 67: 1301-1318.

Stefanović, S., Krueger, L. \& Olmstead, R.G. 2002. Monophyly the Convolvulaceae and circumscription of their major lineages based on DNA sequences of multiple chloroplast loci. American Journal of Botany 89: 1510-1522.

Stefanović, S., Austin, D.F. \& Olmstead, R.G. 2003. Classification of Convolvulaceae: A Phylogenetic Approach. Systematic Botany 28: 791-806.

Stefanović, S., Kuzmina M. \& Costea M. 2007. Delimitation of major lineages within Cuscuta subgenus Grammica 
(Convolvulaceae) using plastid and nuclear DNA sequences. American Journal of Botany 94: 568-589.

Takhtajan, A. 1959. Die Evolution der Angiospermen. Veb Gustav Fischer Verlang, Jena.

Takhtajan, A. 1997. Diversity and classification of flowering plants. Columbia University Press, New York.

Thiers, B. 2020 [continuously updated]. Index Herbariorum: A global directory of public herbaria and associated staff. New York Botanical Garden's Virtual Herbarium. Disponível em http://sweetgum.nybg.org/science/ih/ (acesso em 11-XI-2020).

Welsh, M., Stefanović, S. \& M. Costea. 2010. Pollen evolution and its taxonomic significance in Cuscuta (dodders, Convolvulaceae). Plant Systematic and Evolution 285: 83-101.

Wright, M.A.R., Welsh, M. \& Costea, M. 2011. Diversity and evolution of the gynoecium in Cuscuta (dodders, Convolvulaceae) in relation to their reproductive biology: two styles are better than one. Plant Systematic and Evolution 296: 51-76.

Wright, M.A., Ianni, M.D. \& Costea, M. 2012. Diversity and evolution of pollen-ovule production in Cuscuta (dodders, Convolvulaceae) in relation to floral morphology. Plant Systematics and Evolution 298: 369-389.

Yuncker, T.G. 1922. Revision of the South American species of Cuscuta I. American Journal of Botany 9: 557-575.

Yuncker, T.G. 1923. Revision of the South American species of Cuscuta II. American Journal of Botany 10: $1-17$.

Yuncker, T.G. 1932. The genus Cuscuta. Memoirs of the Torrey Botanical Club 18: 113-331.

Recebido: 23.08 .2020

Aceito: 23.03 .2021

Editor Associado: Ana Rita Giraldes Simões 